\title{
In Silico Investigation of Lactone and Thiolactone Inhibitors in Bacterial Quorum Sensing Using Molecular Modeling
}

\author{
Marawan Ahmed ${ }^{1,2}$, Stefanie Bird ${ }^{1}$, Feng Wang ${ }^{1,2}$ \& Enzo A. Palombo ${ }^{2}$ \\ ${ }^{1}$ eChemistry Laboratory, Faculty of Life and Social Sciences, Swinburne University, Hawthorn, Victoria, \\ Australia \\ ${ }^{2}$ Environment and Biotechnology Centre, Faculty of Life and Social Sciences, Swinburne University, Hawthorn, \\ Victoria, Australia \\ Correspondence: Marawan Ahmed, eChemistry Laboratory, Faculty of Life and Social Sciences, Swinburne \\ University, P.O. Box 218, Hawthorn, Victoria 3122, Australia. Tel: 61-3-9214-8785. E-mail: \\ mmahmed@swin.edu.au
}

Received: June 13, 2013 Accepted: July 21, 2013 Online Published: September 2, 2013

doi:10.5539/ijc.v5n4p9 URL: http://dx.doi.org/10.5539/ijc.v5n4p9

\begin{abstract}
In the present study, the origin of the anti-quorum sensing (QS) activities of several members of a two recently synthesized and in vitro tested classes of lactone and thiolactone based inhibitors were computationally investigated. Docking and molecular dynamic (MD) simulations and binding free energy calculations were carried out to reveal the exact binding and inhibitory profiles of these compounds. The higher in vitro inhibitory activity of the lactone based inhibitors relative to their thiolactone isosteres was verified based on estimating the binding energies, the docking scores and monitoring the stability of the complexes produced in the MD simulations. The strong electrostatic contribution to the binding energies may be responsible for the higher inhibitory activity of the lactone with respect to the thiolactone series. The results of this study help to understand the anti-QS properties of lactone-based inhibitors and provide important information that may assist in the synthesis of novel QS inhibitors.
\end{abstract}

Keywords: quorum sensing, lactone inhibitors, docking, molecular dynamics, AMBER

\section{Introduction}

Treatment of bacterial infections is a major global challenge. Bacteria continue to develop resistance to current anti-bacterial agents and the problem is becoming more wide-spread (Levy, 2001; Levy, 2002; Aiello \& Larson, 2003; Levy \& Marshall, 2004). It is estimated that bacterial resistance can increase mortality and morbidity by a factor of two (Holmberg, Solomon, \& Blake, 1987). The problem is even worse in developing countries where appropriate medical services cannot always be effectively delivered (Okeke et al., 2005). An attractive pathway to resolve the problem of resistance is targeting bacterial quorum sensing (Suga \& Smith, 2003; Swem et al., 2009; Chen et al., 2011; Galloway, Hodgkinson, Bowden, Welch, \& Spring, 2011; Kalia \& Purohit, 2011).

Quorum sensing (QS) is a communication mechanism by which bacterial cells organize biological processes that are not possible with a single bacterium, such as toxin production and biofilm formation (Waters \& Bassler, 2005; Swem et al., 2009; Deep, Chaudhary, \& Gupta, 2011). This mechanism includes binding of specific signal "hormone-like" molecules called "auto-inducers" to specific intracellular or membrane bound receptors (Waters \& Bassler, 2005; Reading \& Sperandio, 2006; Swem et al., 2009). This binding triggers a wide range of intracellular reaction cascades in Gram positive and Gram negative bacteria to carry out the required biological process (Miller \& Bassler, 2001; Reading \& Sperandio, 2006). A typical QS system is composed of three components, (i) A bacterial synthase (e.g. LuxI) that synthesizes the "auto-inducer", (ii) The auto-inducer which is typically an acylhomoserine lactone (AHL) derivative and (iii) A transcription regulatory protein, such as LuxR or its homologues. LuxR protein binds to DNA and activates gene expression once the level of the AHL reaches a critical threshold depending on the bacterial population density (Rasmussen et al., 2005; Bottomley, Muraglia, Bazzo, \& Carfì, 2007).

Various mechanisms of this AHL induced QS activation have been proposed and three mechanisms are the most widely accepted. In the first mechanism, the AHL induced conformational changes on LuxR enable LuxR to 
bind DNA and trigger the transcription process (Zhang et al., 2002; Rasmussen et al., 2005). In the second mechanism, the AHL induced LuxR conformational changes relieve the repressor effect exerted by LuxR on the target genes and enable gene transcription (Fuqua, Winans, \& Greenberg, 1994; Sjöblom, Brader, Koch, \& Palva, 2006). In the third mechanism, extracellular AHL is detected by membrane bound receptors that trigger a wide range of intracellular reactions leading to gene expression (Swem, Swem, Wingreen, \& Bassler, 2008; Swem et al., 2009).

Bacteria cannot easily develop an acquired resistance against QS inhibitors. As a result, QS inhibition is seen as an excellent weapon to fight against bacteria (Bottomley, Muraglia, Bazzo, \& Carfí, 2007; Swem et al., 2009). A number of distinct methods have been described to inhibit QS. In one of such methods, the AHL synthase is inhibited by small molecule analogues of organic compounds involved in AHL biosynthesis (Geske, O'Neill, \& Blackwell, 2008; Galloway, Hodgkinson, Bowden, Welch, \& Spring, 2011; Galloway, Hodgkinson, Bowden, Welch, \& Spring, 2012). Enzymatic hydrolysis of the AHL molecule by acylases, hydrolases and lactonases has been reported as an excellent defense mechanism for other organisms against bacteria (Geske, O'Neill, \& Blackwell, 2008; Galloway, Hodgkinson, Bowden, Welch, \& Spring, 2011; Galloway, Hodgkinson, Bowden, Welch, \& Spring, 2012). The third and most widely investigated method is the use of small AHL analogues that competitively inhibit AHL binding to the LuxR proteins and their homologues, such as the LasR protein (Geske, Wezeman, Siegel, \& Helen, 2005; Geske, O’Neill, Miller, Mattmann, \& Helen, 2007; Estephane et al., 2008; Chen et al., 2011; Galloway, Hodgkinson, Bowden, Welch, \& Spring, 2011; Galloway, Hodgkinson, Bowden, Welch, \& Spring, 2012; Skovstrup et al., 2013). These classes of inhibitors are referred to as "AHL antagonists". In the present study, two in vitro tested lactone and thiolactone series of AHL antagonists are computationally investigated to understand the origin of their anti-QS activities.

The most commonly investigated AHL antagonists are those belonging to lactone, thiolactone and furanone classes of organic compounds (Geske, Wezeman, Siegel, \& Helen, 2005; Geske, O'Neill, Miller, Mattmann, \& Helen, 2007; Estephane et al., 2008; Chen et al., 2011; Galloway, Hodgkinson, Bowden, Welch, \& Spring, 2011; McInnis \& Blackwell, 2011; Galloway, Hodgkinson, Bowden, Welch, \& Spring, 2012; Skovstrup et al., 2013). This is due to the structural similarities between these molecules and the naturally occurring AHL auto-inducers. These auto-inducers can have different structures depending on the producing organism. In most cases, the auto-inducer is composed of a five-membered lactone head and an acyl group spacer connecting this head to a hydrophobic chain tail. The length of the tail and its chemical structure differ between AHL derivatives and can affect the potency and the intrinsic activity (agonist or antagonist) of a given AHL (Geske, O'Neill, Miller, Mattmann, \& Helen, 2007; Nasser \& Reverchon, 2007; Swem et al., 2009; Galloway, Hodgkinson, Bowden, Welch, \& Spring, 2011). This may facilitate the tuning of the effect for a given inhibitor or inducer so that it can selectively inhibit or activate a particular type of bacterium. Some authors suggested the ability of several molecules to inhibit QS although they are not structurally related to AHL (Soulère, Sabbah, Fontaine, Queneau, \& Doutheau, 2010).

Unfortunately, computational studies on this important class of inhibitors are rare which may be due to the limited availability of crystal structures of the LuxR proteins complexed with their corresponding antagonists (Soulère, Frezza, Queneau, \& Doutheau, 2007; Estephane et al., 2008; Soulère, Guiliani, Queneau, Jerez, \& Doutheau, 2008; Sabbah et al., 2012). The need for detailed investigation of QS inhibition at the molecular level is necessary for the understanding of QS process and the future development of effective drugs. In the current study, the binding mode of a recently synthesized and tested thiolactone group of AHL antagonists against LuxR proteins (Swem et al., 2009) was investigated. Docking and molecular dynamics (MD) simulations were carried out against a recently resolved X-ray crystal structure of LuxR protein from Chromobacterium violaceum $(C$. violaceeum). The $C$. violaceum LuxR protein (CviR) was co-crystallized with an inhibitor from a similar study but having a lactone ring instead of thiolactone, i.e., sulphur has been replaced by its isosteric oxygen atom (Chen et al., 2011). In addition to the reported thiolactone series, the corresponding lactone analogues are computationally investigated to understand the differences in binding between the two groups. Also, it has been shown that the thiolactone analogue of the co-crystallized inhibitor is less effective than the lactone inhibitor, a detailed analysis is carried out to understand the basis of this difference.

\section{Methods and Computational Details}

The chemical structure of the lactone and thiolactone backbone skeleton is given in Figure 1. When the $\mathrm{X}$ atom in the penton ring is oxygen, i.e. $\mathrm{X}=\mathrm{O}$, the structures are lactones, whereas the structures become thiolactones if $\mathrm{X}=\mathrm{S}$ in the same figure. The R-group at the end of the chain in the backbone structure is replaced by different sixteen groups as listed in the figure, which in total produced 32 compounds: 16 thiolactones and 16 lactones. The thiolactone series is denoted as "TL", the lactone series is denoted as " $\mathbf{L}$ " as marked in the same figure, in 
which the original co-crystallized lactone inhibitor is denoted as $\mathbf{L 3}$ and its thiolactone isostere is denoted as TL3.

In the protein preparation, the crystal structure of CviR (a LuxR protein) co-crystallized with chlorolactone (L3) antagonist was taken from the PDB (PDB entry: 3QP5) (Chen et al., 2011). Figure 2 gives a three-dimensional (3D) representation of the CviR protein monomer. The complex was prepared using the protein preparation wizard in Maestro 9.2 (Maestro 9.2, Schrödinger, LLC, New York, NY, 2012) similar to our previous studies (Ahmed et al., 2013; Sadek et al., 2013). The crystallized protein structure is a tetramer, one chain is kept, and others are deleted, the kept chain is further saturated by hydrogen atoms and the missing residues were added and refined using Prime 3.0 (Prime version 3.0, Schrödinger, LLC, New York, NY, 2012). The N-acetyl (ACE) and $\mathrm{N}$-methyl amide (NMA) groups were added to cap the uncapped $\mathrm{N}$ and $\mathrm{C}$ termini respectively. H-bond network optimization was carried out assuming a neutral $\mathrm{pH}$. The protonation states of titratable amino acids were assigned at the same $\mathrm{pH}$. An all atom impref minimization step was carried out to remove unfavorable steric clashes until a convergence was reached or with a maximum RMSD of $0.3 \AA$ from the original conformation. No steric clashes were reported after the final minimization step.

Once the protein structure is set up, a receptor grid was prepared with the receptor grid generation module in Glide 5.8 (Glide 5.8, Schrödinger, LLC, New York, NY, 2012). The binding site was determined as a box around the ligand that was centered inside the box. Four H-bonds constraints with the nearby residues (Tyr80, Trp84 Asp97, and Ser155) were set in the grid preparation.

Ligand molecules were optimized at the RM1 (Rocha, Freire, Simas, \& Stewart, 2006) semiempirical level of theory as implemented in the Semiempirical module in Maestro 9.2. Ligand partial atomic electrostatic potential charges (ESP) charges were assigned at the HF/cc-pVTZ level of theory using Jaguar (Jaguar 7.9, Schrödinger, LLC, New York, NY, 2012).<smiles>[R]OCCCC(=O)NC1[X]CCC1</smiles>

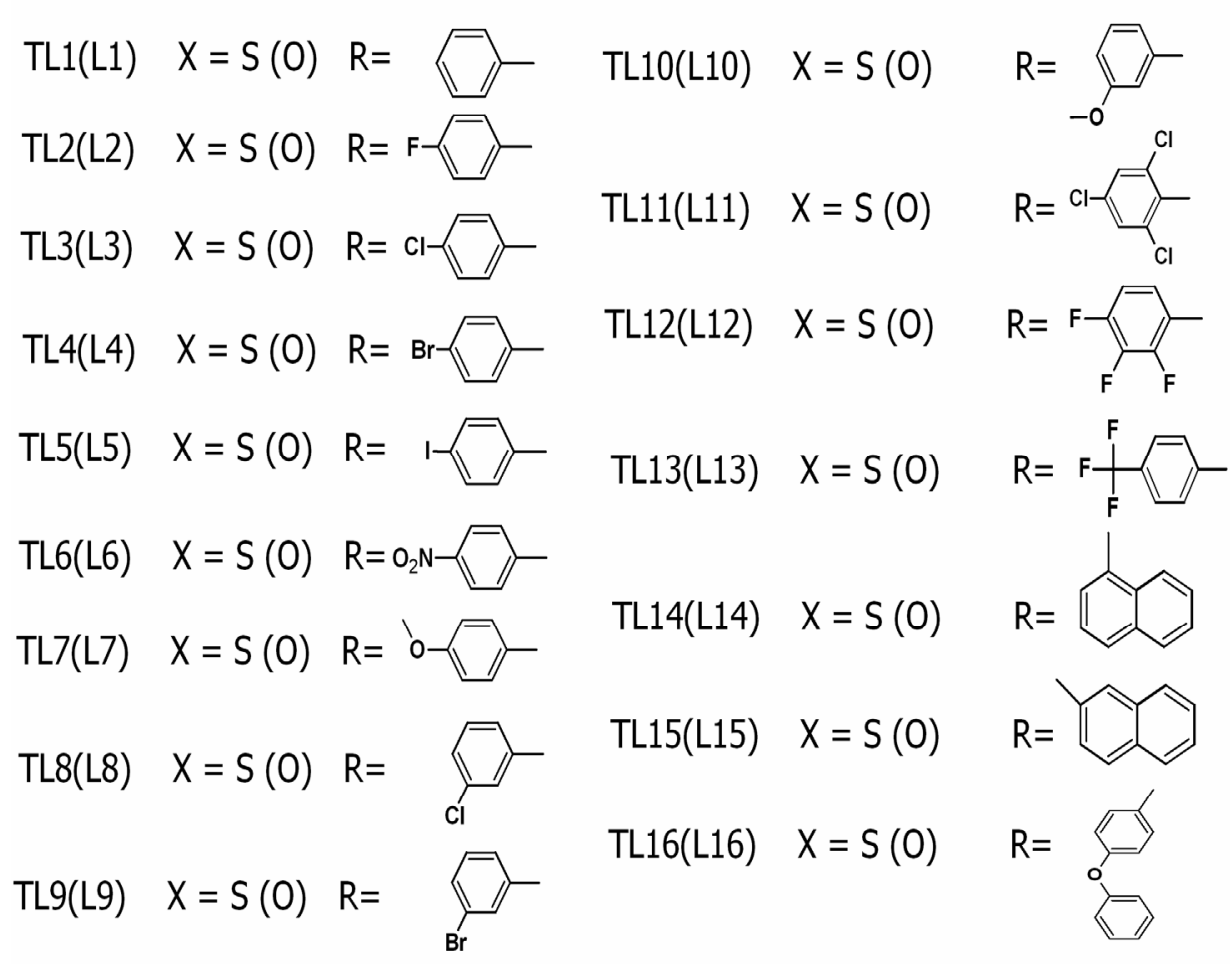

Figure 1. Two dimensional (2D) structures of the lactone $(X=O)$ and thiolactone $(X=S)$ inhibitors under study 


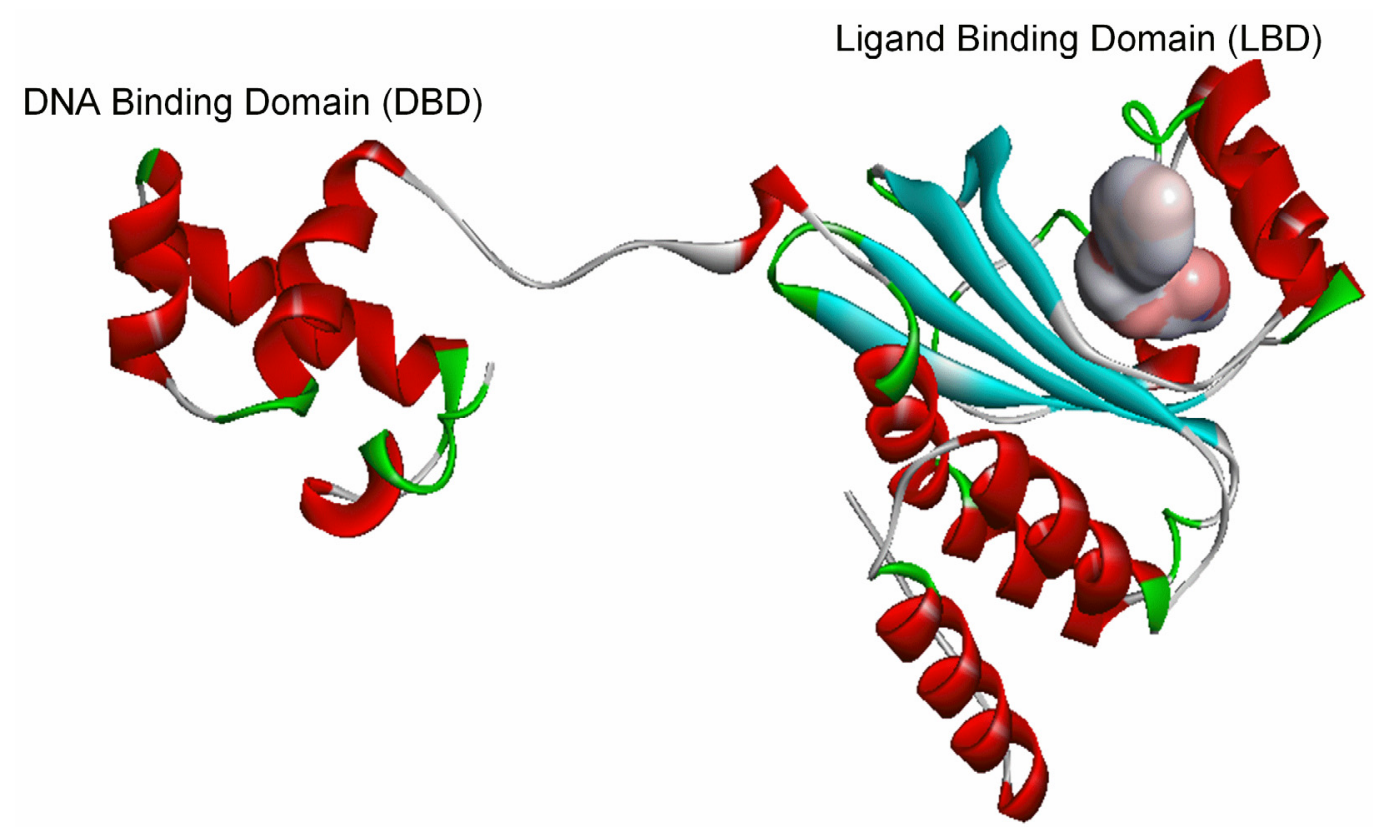

Figure 2. Three dimensional (3D) ribbon representation for the CviR monomer. Solid surface in the LBD represent the exact binding location of the inhibitors

Next, docking and scoring of the study employed the flexible ligand docking, which was performed through the Glide extra precision mode (Glide XP) (Friesner et al., 2006). In order to increase the sampling space, a maximum of 50.000 initial ligand poses were kept in the initial phase of docking. A scoring window of poses within $1000 \mathrm{kcal} \cdot \mathrm{mol}^{-1}$ from the best scoring pose were retained, from which a maximum of 800 poses per ligand were subjected to 200 steps of energy minimization. A potential ligand pose was considered only when at least three of the four predetermined H-bond constraints were satisfied. Rescoring the docked poses was done using the Prime/MM-GBSA module in Prime 3.0; residues within $6 \AA$ of the ligand were considered flexible.

Finally, molecular dynamics (MD) simulations were conducted for the co-crystallized lactone inhibitors and its thiolactone analogues with both the dimeric and the monomeric forms of the CviR protein, i.e. four inhibitor-protein complexes were simulated. That is, the L3/TL3-CviR monomer complexes and the L3/TL3-CviR dimer complexes. To remove any potential bias due to different starting configurations, the TL3 complexes were obtained by mutating the oxygen atom of the experimentally resolved $\mathbf{L} \mathbf{3}$ complexes to a sulphur atom.

The structure preparation and the following MD simulations were performed using AMBER 12 software package applying the ff03 force field (Duan et al., 2003). Single point calculations of the corresponding inhibitors were performed at the HF/6-31G* using the Gaussian 09 program. The inhibitor charges and other parameters were obtained using the RESP fitting (Bayly, Cieplak, Cornell, \& Kollman, 1993) procedures and the general AMBER force field (GAFF) (Wang, Wolf, Caldwell, Kollman, \& Case, 2004). The complexes were then solvated in a box of TIP3P (Jorgensen, Chandrasekhar, Madura, Impey, \& Klein, 1983) water with a buffer size of $15 \AA$ and were neutralized by counter ions.

Each system was then subjected to four consecutive minimization steps. In each step, water molecules and ions were allowed to move freely for a 1000 steps of steepest descent minimization followed by 4000 steps of conjugate gradient minimization holding protein and inhibitor atoms constrained to their original positions by a force constant of $100 \mathrm{kcal} \cdot \mathrm{mol}^{-1} \AA^{-2}$, then gradually releasing the force constraints to 50,5 and zero (no constraints) $\mathrm{kcal} \cdot \mathrm{mol}^{-1} \AA^{-2}$, respectively. Following minimization, two consecutive steps of heating and equilibration were performed. Each system was gradually heated in the NVT ensemble from $0 \mathrm{~K}$ to $300 \mathrm{~K}$ for 30 ps with a time step of $1 \mathrm{fs}$, applying a force constant of $10 \mathrm{kcal} \cdot \mathrm{mol}^{-1} \AA^{-2}$ on the protein and inhibitor coordinates. Langevin dynamics with the collision frequency $\gamma$ of $1 \mathrm{ps}^{-1}$ for temperature control was employed. A further $1 \mathrm{~ns}$ simulation in the NPT ensemble was performed to equilibrate the system density by applying a time step of $2 \mathrm{fs}$, which required the use of SHAKE algorithm (Ryckaert, Ciccotti, \& Berendsen, 1977) to constrain all bonds involving hydrogen atoms. The temperature was controlled using Langevin dynamics with the collision 
frequency $\gamma$ of $1 \mathrm{ps}^{-1}$ and is kept at $300 \mathrm{~K}$. The pressure was kept at 1 bar by applying a Berendsen barostate with a pressure relaxation time of 1 ps. Each system was again relaxed in the NVT ensemble for $20 \mathrm{~ns}$ followed by 30 ns production simulation at $300 \mathrm{~K}$ using Berendsen temperature control (Berendsen, Postma, van Gunsteren, DiNola, \& Haak, 1984). In all simulation steps, long-range electrostatics were computed using the particle mesh Ewald (PME) and a 12 Å real space cut-off (Darden, York, \& Pedersen, 1993). The edge effect was removed by applying periodic boundary conditions. For MD simulations of the monomeric chains, weak constraining forces were applied on the DNA binding domain plus the flexible coil segments of the monomeric chain. All MD simulations were carried out using the PMEMD module of AMBER12. For the binding energy evaluation from the trajectory, the MM/PBSA module of AMBER12 was used and using every second frame collected from the MD simulations, i.e. around 3750 snapshots were used (Miller et al., 2012).

\section{Results and Discussion}

\subsection{Docking and Scoring}

To the best of our knowledge, the first available X-ray crystal structure for a member of the LuxR family of proteins co-crystallized with a pure antagonist is the CviR protein from Chromobacterium violaceum (PDB code: 3QP5) (Chen et al., 2011). In that study, CviR was co-crystallized with various ligands of either agonistic or antagonistic activities. Agonist binding to CviR results in conformational changes and activation of the dimer to bind DNA and trigger DNA transcription. The ligand induced conformational changes determine the intrinsic activity of a given ligand to be either an agonist or an antagonist. In addition, it has been shown that subtle ligand structural differences can affect the potency and the intrinsic activity of a given ligand dramatically (Geske, O'Neill, Miller, Mattmann, \& Helen, 2007; Nasser \& Reverchon, 2007; Swem et al., 2009; Galloway, Hodgkinson, Bowden, Welch, \& Spring, 2011). Moreover, the same ligand can work as an agonist or an antagonist depending on the protein homologue and the bacterial strain (Geske, O'Neill, Miller, Mattmann, \& Helen, 2007; Nasser \& Reverchon, 2007; Swem et al., 2009; Galloway, Hodgkinson, Bowden, Welch, \& Spring, 2011). These unique properties urge further and extensive theoretical and experimental work to shed the light on the complex mechanism that controls QS signaling.

Figure 2 presents a solid ribbon representation of a CviR protein monomer. The protein is made of two distinct domains, a Ligand Binding Domain (LBD) and a DNA Binding Domain (DBD) and the two domains are connected by a short flexible coil. The LBD is the bigger domain and is composed of $\alpha$-helices and $\beta$-sheets while the DBD is composed of a few $\alpha$-helices. The exact ligand binding site is shown as a solid surface inside the LBD.

AHLs or their analogues are characterized by a unique "sperm-like" structure composed of two parts, head and tail. The lactone head is able to form an H-bond with the nearby Trp84 residue, while the acyl group forms H-bonds with Asp97, Tyr80 and Ser155. The tail part is buried in a hydrophobic pocket made of Val, Leu and Ile residues. Figure 3 shows two 2D ligand interaction diagrams for an agonist (PDB code: 3QP1) and an antagonist (PDB code: 3QP5).

Table 1 reports the docking scores for the inhibitors under study using the conventional docking scores and the Prime-MM/GBSA scores. Inhibitors are given in the table according to their XP Gscore. From the correlation with the available experimental $\mathrm{IC}_{50}$ data, the Prime MMGBSA DG bind vdW score achieved the best correlation with experimentally measured $\mathrm{IC}_{50}\left(\mathrm{r}_{(\text {pearson })}=0.52\right)$. Glide Emodel performed reasonably well $\left(\mathrm{r}_{\text {(pearson })}\right.$ $=0.49$ ). The thiolactone derivatives showed overall lower scores than their corresponding lactone analogues, which is consistent with the experimental findings. Only the XP Gscore was able to identify the original lactone inhibitor (L3) followed by the TL12 thiolactone derivative to be the best inhibitors among the two series.

Figure 4 represents the 2D and 3D interaction diagrams of some selected antagonists with the CviR receptor. In general, antagonists binding modes to the receptor are similar to the original co-crystallized antagonist. This is a result of the strict docking criteria which are applied for accepting poses. The lactone carbonyl forms a direct H-bond with the conserved Trp84 residue, the acyl group -NH forms an H-bond with Asp97 and the carbonyl oxygen forms H-bonds with Tyr80 and Ser155. As the libraries are focused, subtle ligand differences which are correlated directly with inhibitory activity need to be paid greater attention.

The main difference between the two libraries is the isosteric replacement of the "S" atom in the TL series by an "O" atom in the $\mathbf{L}$ series. The observed activity differences between the two libraries may be related to the $\mathrm{H}$-bond strength that may exist between the sulphur or oxygen ring atoms and the nearby $-\mathrm{C}_{(7)} \mathrm{H}$ of $\operatorname{Trp} 84$. However, it is known that heterocyclic H-bond acceptors are grouped in the "weak H-bond" category of acceptors (Schwobel, Ebert, Kuhne, \& Schuurmann, 2009). Therefore, potential large effects of this H-bond (if any) are not expected. The effect of this substitution is discussed in detail in section 3.2. 
The major difference between any pair of inhibitors within the same library ( $\mathbf{T L}$ or $\mathbf{L}$ ) is the chemical structure of the hydrophobic tail chain. Studies have indicated that the structure and the length of this chain can affect the potency and the intrinsic activity of a given ligand (Geske, O'Neill, Miller, Mattmann, \& Helen, 2007; Nasser \& Reverchon, 2007; Swem et al., 2009; Galloway, Hodgkinson, Bowden, Welch, \& Spring, 2011). In the two inhibitor libraries, the terminal aromatic group forms a direct, sandwich type $\pi-\pi$ stacking interaction with Tyr88 aromatic ring. Assuming all inhibitors have a similar binding mode, the overall binding strength (within a given library) is directly correlated with the strength of this $\pi-\pi$ stacking interaction.
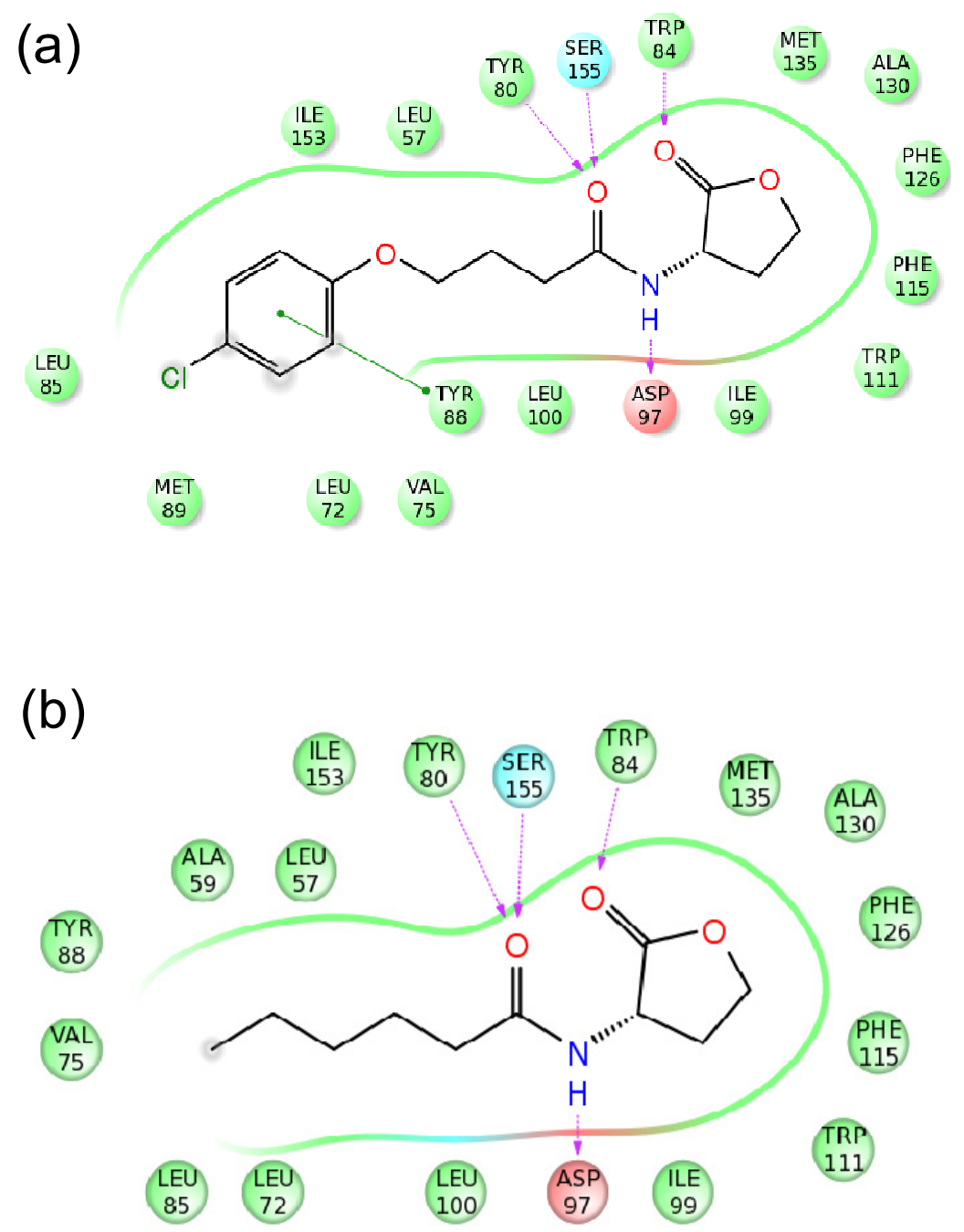

Figure 3. 2D ligand interaction diagrams for (a) a potential CviR antagonist (PDB code: 3QP5) and (b) a potential CviR agonist (PDB code: 3QP1) 

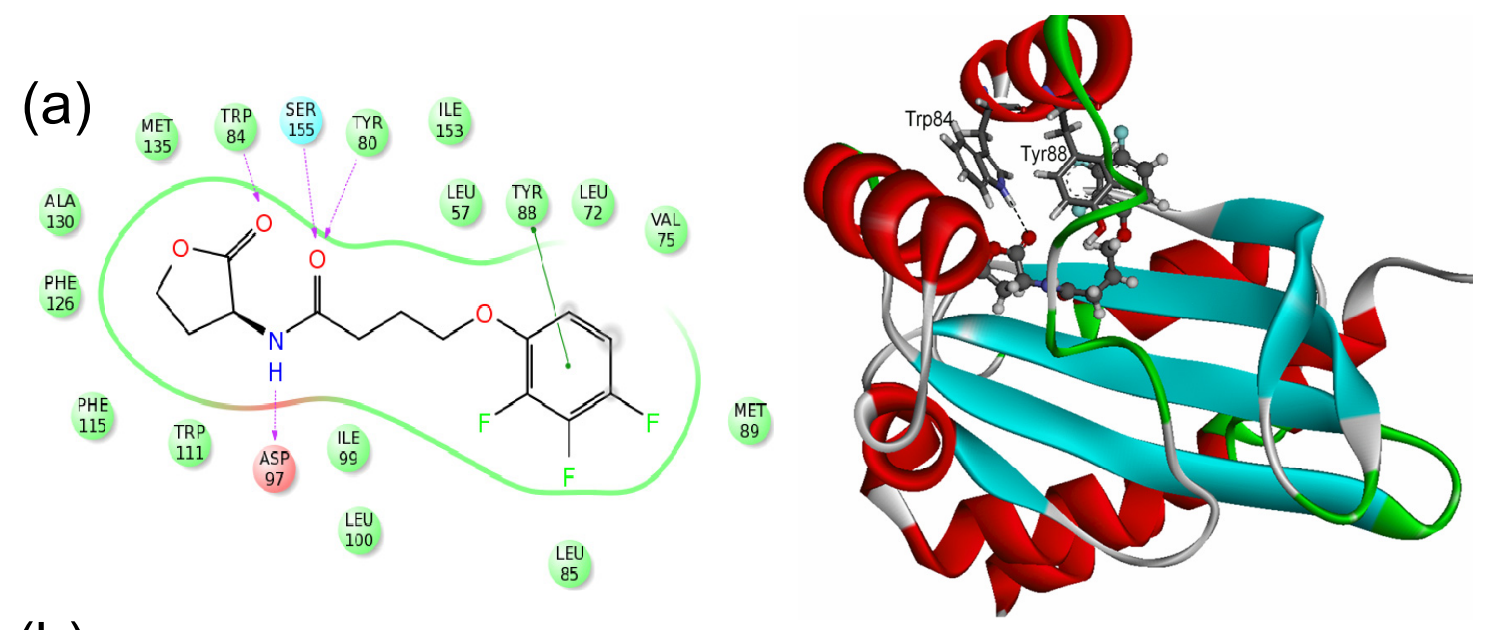

(b)
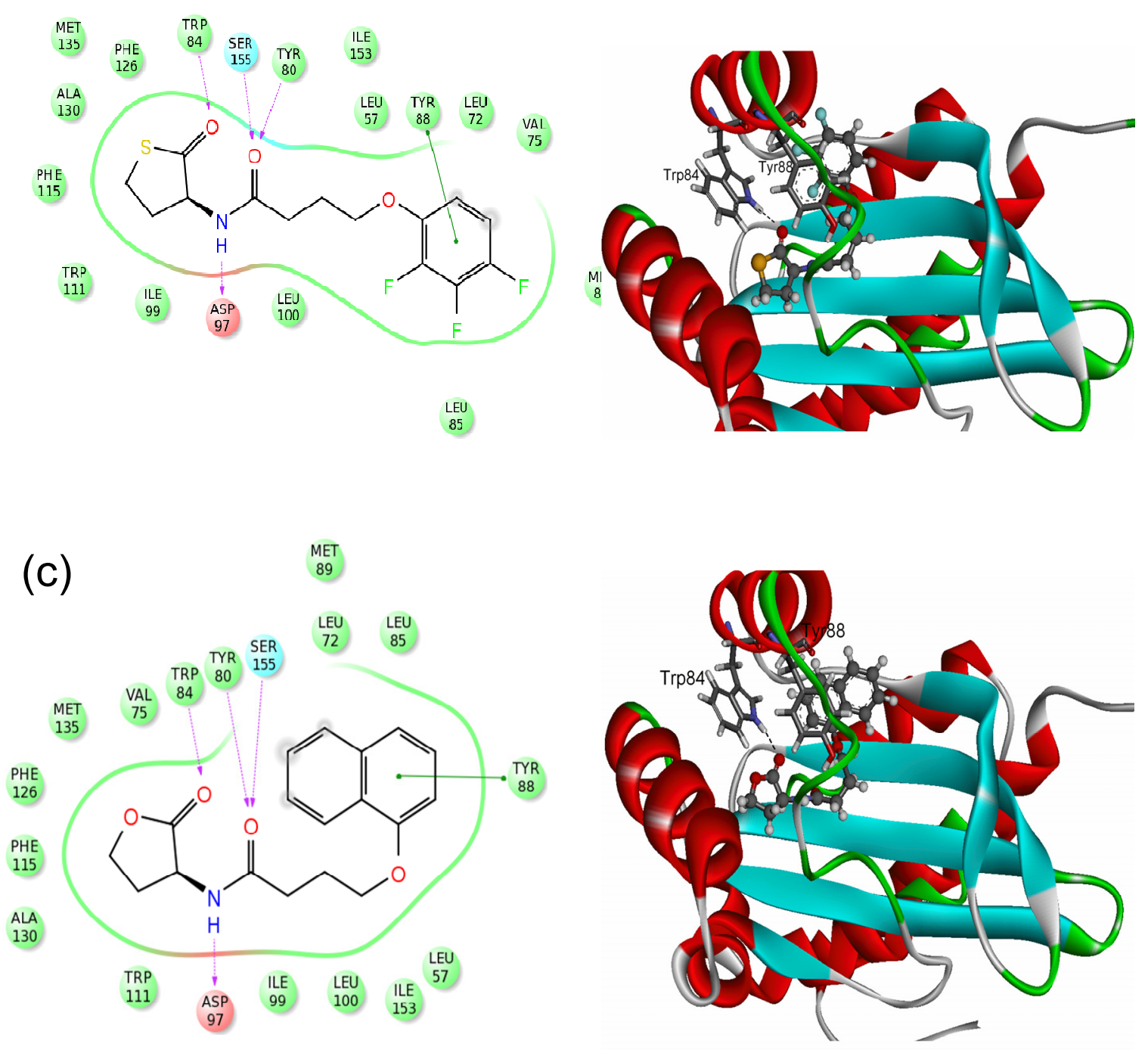

Figure 4. 2D and 3D ligand interactions for some selected inhibitors under study in the CviR binding site (a) L12, (b) TL12 and (c) L14. In the 3D figures, the inhibitors are in a ball and stick representation and the amino acid residues are in a stick representation 
Table 1. Selected binding energy scores together with the available in vitro measured $\mathrm{IC}_{50}$ values for the inhibitors under study ranked according to the XP Gscore

\begin{tabular}{|c|c|c|c|c|c|c|c|}
\hline Inhibitors & $\mathrm{IC}_{50}(\mu \mathrm{M})^{\mathrm{a}}$ & XP GScore & XP LipophilicEvdW & $\begin{array}{c}\mathrm{XP} \\
\text { Electrostatic }\end{array}$ & $\begin{array}{l}\text { Glide } \\
\text { Emodel }\end{array}$ & $\begin{array}{c}\text { Prime MMGBSA } \\
\text { DG bind }\end{array}$ & $\begin{array}{c}\text { Prime MMGBSA DG } \\
\text { bind vdW }\end{array}$ \\
\hline L14 & - & -10.28 & -4.90 & -1.16 & -91.15 & -99.19 & -49.53 \\
\hline L15 & - & -10.25 & -5.12 & -1.19 & -96.06 & -102.41 & -47.95 \\
\hline L12 & - & -10.02 & -4.19 & -1.19 & -89.99 & -100.53 & -46.46 \\
\hline L11 & - & -9.71 & -4.66 & -1.19 & -93.41 & -116.59 & -51.84 \\
\hline L4 & - & -9.50 & -4.60 & -1.20 & -94.81 & -98.70 & -45.54 \\
\hline L3 & 0.38 & -9.49 & -4.63 & -1.20 & -90.40 & -105.54 & -46.19 \\
\hline TL12 & 0.63 & -9.43 & -4.14 & -1.07 & -80.56 & -104.45 & -44.09 \\
\hline L9 & - & -9.40 & -4.50 & -1.18 & -96.34 & -107.02 & -48.73 \\
\hline L13 & - & -9.40 & -4.40 & -1.21 & -70.66 & -101.06 & -47.33 \\
\hline L5 & - & -9.38 & -4.64 & -1.17 & -95.11 & -106.60 & -48.48 \\
\hline L8 & - & -9.36 & -4.48 & -1.17 & -92.92 & -102.88 & -44.60 \\
\hline TL15 & 5.00 & -9.34 & -4.76 & -1.09 & -89.31 & -102.13 & -46.57 \\
\hline L2 & - & -9.34 & -4.29 & -1.18 & -91.56 & -94.47 & -43.61 \\
\hline TL14 & 4.00 & -9.32 & -4.50 & -1.05 & -83.97 & -101.76 & -46.95 \\
\hline TL1 & - & -9.11 & -4.27 & -1.18 & -89.77 & -92.72 & -43.31 \\
\hline TL11 & 1.40 & -9.08 & -4.49 & -1.09 & -86.47 & -118.22 & -51.14 \\
\hline L10 & - & -8.76 & -4.31 & -1.10 & -72.97 & -99.16 & -45.17 \\
\hline TL3 & 1.10 & -8.61 & -4.19 & -1.05 & -79.07 & -104.49 & -45.00 \\
\hline TL4 & 1.80 & -8.60 & -4.25 & -1.07 & -82.58 & -101.97 & -45.27 \\
\hline TL2 & 2.10 & -8.58 & -3.86 & -1.06 & -81.62 & -100.98 & -39.87 \\
\hline TL5 & 1.40 & -8.53 & -4.27 & -1.07 & -83.29 & -102.32 & -45.68 \\
\hline TL8 & 2.10 & -8.51 & -3.97 & -0.98 & -81.19 & -115.31 & -48.53 \\
\hline TL9 & 2.70 & -8.36 & -4.11 & -1.04 & -80.41 & -109.05 & -41.12 \\
\hline TL13 & 3.40 & -8.20 & -3.75 & -1.02 & -69.40 & -95.52 & -40.07 \\
\hline TL1 & 2.60 & -8.18 & -3.91 & -1.07 & -79.01 & -96.20 & -42.11 \\
\hline L6 & - & -8.05 & -3.92 & -1.13 & -77.15 & -90.41 & -42.70 \\
\hline L7 & - & -7.81 & -4.26 & -1.09 & -74.02 & -99.39 & -44.11 \\
\hline L16 & - & -7.78 & -4.66 & -1.18 & -76.10 & -101.75 & -48.56 \\
\hline TL10 & 37.00 & -7.67 & -3.92 & -0.94 & -70.76 & -97.99 & -37.71 \\
\hline TL6 & 2.50 & -7.29 & -4.12 & -1.14 & -75.55 & -112.28 & -47.43 \\
\hline TL7 & 11.00 & -6.95 & -4.05 & -0.88 & -65.21 & -98.33 & -38.84 \\
\hline TL16 & 3.90 & -5.69 & -3.95 & -0.84 & -77.05 & -109.95 & -49.65 \\
\hline $\mathrm{r}_{(\text {(Parson) }}{ }^{\mathrm{b}}$ & & 0.30 & 0.25 & 0.44 & 0.49 & 0.34 & 0.52 \\
\hline
\end{tabular}

${ }^{a}$ See Chen et al. (2011).

${ }^{\mathrm{b}}$ Pearson correlation coefficient between the in silico calculated docking scores and the in vitro measured $\mathrm{IC}_{50}$ values.

As can be seen in Table 1, substitution with Electron Donating Groups (EDG), such as methoxy groups, resulted in a dramatic reduction in the activity regardless of the position of this substitution. They also had the overall worst inhibitory effect and docking scores. For example, the $\mathrm{IC}_{50}$ of -meta (TL10) and -para (TL7) substituted 
methoxy group derivatives are $37 \mu \mathrm{M}$ and $11 \mu \mathrm{M}$, respectively. On the other hand, Electron Withdrawing Group (EWG) derivatives, such as halogenated derivatives, have the highest inhibitory effect and best docking scores as well. For example, the top scoring inhibitors (according to the Glide XP score) were the L3 and the TL12 inhibitors, which have $\mathrm{IC}_{50}$ values of $0.38 \mu \mathrm{M}$ and $0.63 \mu \mathrm{M}$, respectively. The lactone isostere of TL12, the L12 antagonist, exhibited a better XP Gscore (-10.02) than TL12 (-9.43). These findings suggest that the halogenated derivatives, particularly the poly-halogenated ones, to be better candidates for further synthesis and biological testing.

\subsection{Molecular Dynamic Simulations}

A difficult challenge in performing a meaningful MD simulation for LuxR proteins (including CviR) is their inherent flexibility. This inherent flexibility is obvious knowing that the protein can adopt different conformations depending on their activation states as well as the accompanying ligand. This flexibility enables different proteins to carry out their functions properly (Ho \& Agard, 2009). CviR is a homo-dimer composed of two identical and overlapping chains of about 250 amino acids each. Each monomeric chain is composed of an LBD connected to a DBD through a flexible coil.

An accurate measure to assess the stability of the protein complexes during MD simulations is the root mean square deviations (RMSD). Figure 5 (a-b) displays the RMSD plots for the $\mathrm{C} \alpha$ atoms of each protein in the production simulation period. As can be seen in the plots, the $\mathbf{L} \mathbf{3}$ complexes, in both the monomeric and dimeric forms, have higher stabilities than their TL3 counterparts. The average RMSD for L3-CviR dimer is $\sim 1.6-1.8 \AA$. For the TL3-CviR dimer complex, the average RMSD value is higher with an average value of $\sim 4 \AA$. This illustrates the enhanced stability of the CviR dimer with $\mathbf{L 3}$ over TL3. Interestingly, the same is true for the monomeric case such that the $\mathbf{L} \mathbf{3}$ complex with the monomeric CviR is more stable than its TL3 counterpart. This reduced stability of the $\mathbf{T L}$ complexes relative to the $\mathbf{L}$ complexes is attributed to the fluctuation in the DBD not the LBD as we will see in the following section.

To examine the origin of this reduced stability of the TL3 complexes with respect to the $\mathbf{L 3}$ complexes, a more detailed analysis on a per-residue basis was conducted using the per-residue heavy atoms RMSFs (root mean square fluctuations). Figure 6(a-b) displays the heavy atoms RMSF plots of the four complexes during the simulation time. As can be seen, the $\mathbf{L 3}$ complexes show enhanced stability over the TL3 complexes. For the CviR dimer complexes, the LBDs of both chains (A and B) possess an overall lower RMSF during the simulation period than the DBDs. For the monomeric complexes with L3 and TL3, and as a result of the weak constraints applied on the "DBD+coil" segment of the monomeric chains, the whole monomer is of a comparable RMSF value. The enhanced flexibility of the DBD segment of the dimeric protein is expected given the fact that this segment is responsible for binding to DNA upon activation (Stauff \& Bassler, 2011). It would be also interesting to investigate the detailed binding event of this segment to DNA upon agonists or antagonists binding. However, such a complex process is beyond the capability of conventional MD simulation and other MD paradigms, such as accelerated MD, may be more suitable (Voter, 1997). Research in this direction is currently in progress.

It is important to study the stability of the observed H-bonds as a function of the simulation time. Thus, Figure 7 (a-d) displays some selected H-bonds monitored during the simulation time for the four complexes. The first and most important H-bond is the one formed with Trp84 residues and it has been already identified in the docking section. As can be seen in Figure 7, the average value for this H-bond is $\sim 1.9-2.3 \AA$ for all complexes. The $\mathbf{L 3}$ complexes have less fluctuation during the simulation time than their TL3 counterparts. The same is true for the H-bonds formed with the Tyr80 residue in all complexes. For the L3 and TL3 complexes with the monomeric CviR chains, higher fluctuations of up to $3.5 \AA$ (L3) and $4.3 \AA$ (TL3) were observed. 

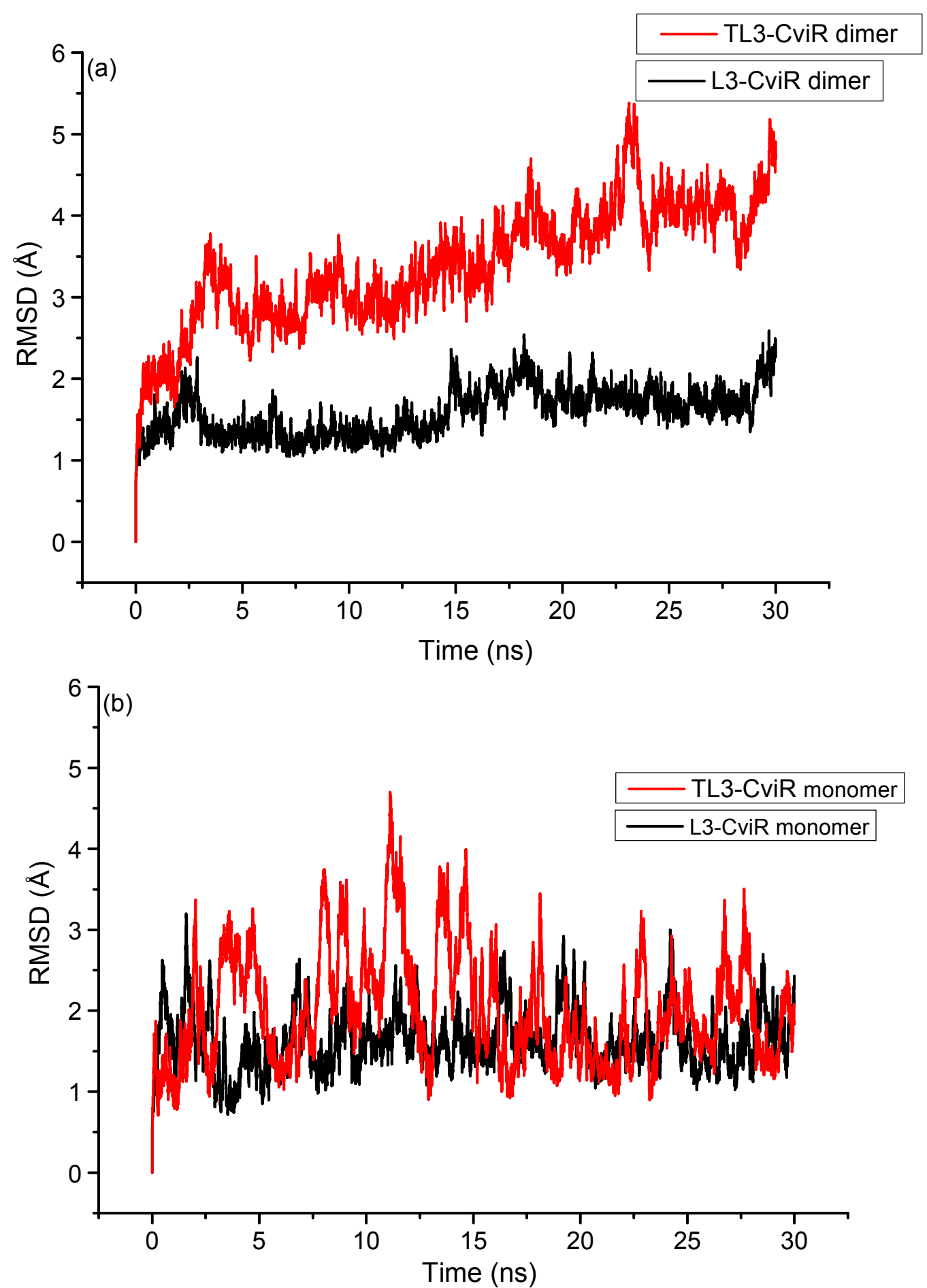

Figure 5. RMSD plots for the protein backbone $\mathrm{C} \alpha$ atoms during the $30 \mathrm{~ns}$ production simulation for (a) dimer complexes and (b) monomer complexes 

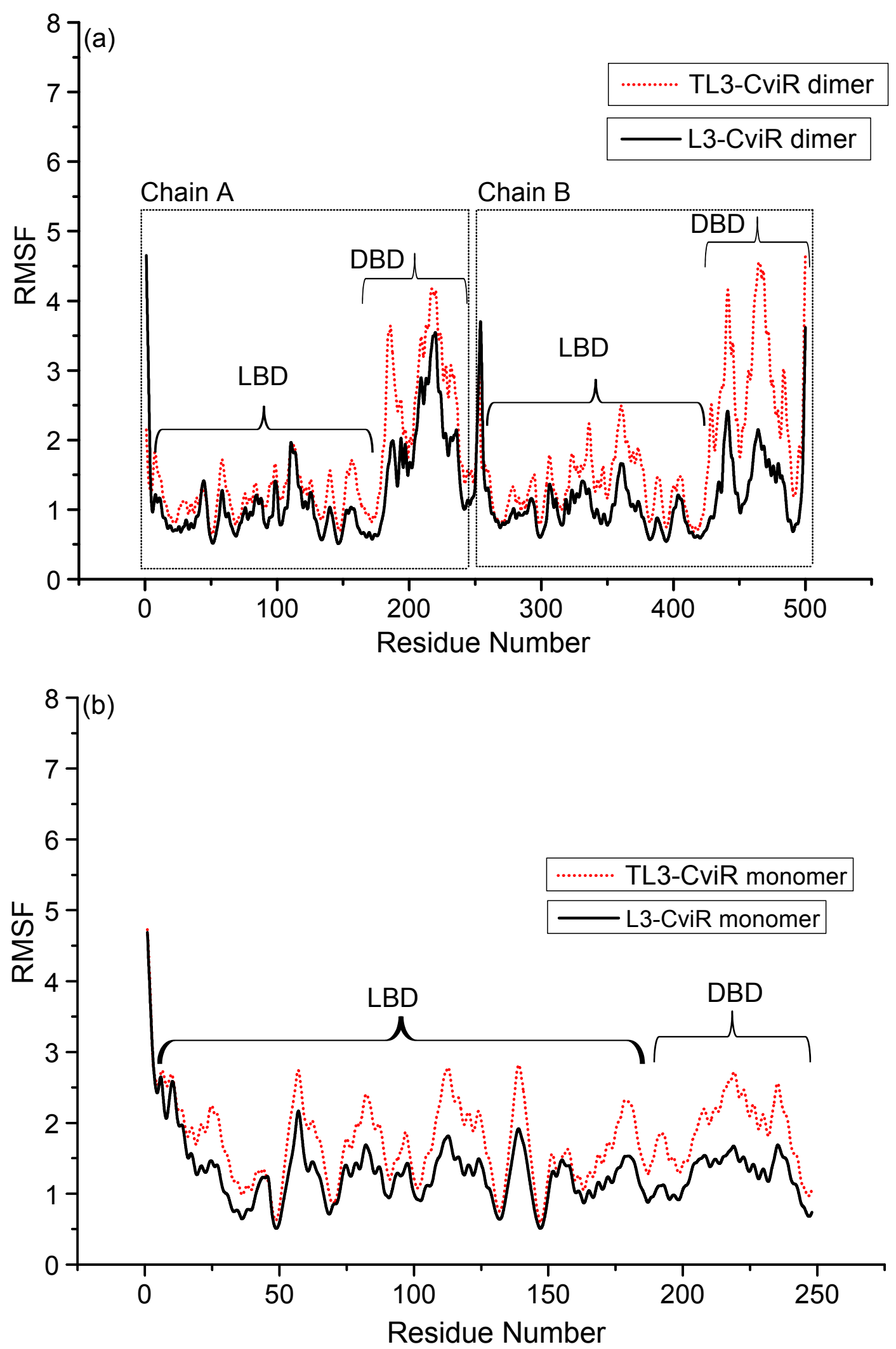

Figure 6. Per-residue heavy atoms RMSF plots during the 30 ns production simulation for (a) dimer complexes and (b) monomer complexes 

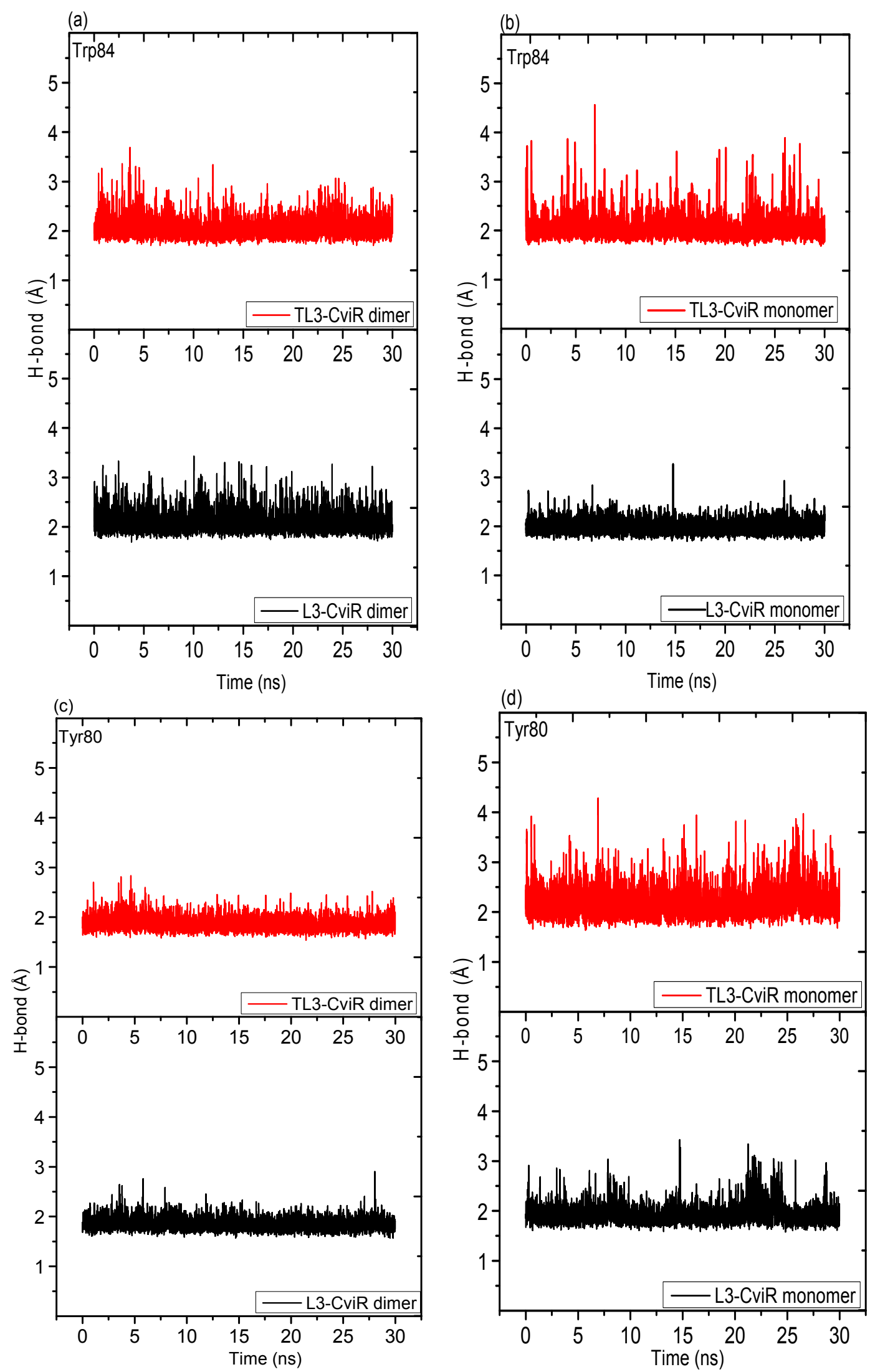

Figure 7. Selected H-bonds distances monitored during the $30 \mathrm{~ns}$ production simulations for $(\mathrm{a}, \mathrm{c})$ dimer complexes and $(b, d)$ monomer complexes 


\subsection{Total and Decomposed MM-PB/GBSA Binding Energies}

Table 2 reports the binding energy scores for $\mathbf{L 3}$ and TL3 inhibitors according to the AMBER-MMPB/GBSA scores as implemented in AMBER12. The AMBER-MMPB/GBSA binding energy scores take the advantage of statistical averaging over many potential conformations that are produced from the MD trajectories. In the AMBER-MMPB/GBSA calculations, only the inhibitor-dimer complexes are considered. To further enhance statistical precision and knowing that each complex contains two inhibitors, each inhibitor is treated separately as a ligand in a separate run. Final data reported are the average values of the two independent AMBER-MMPB/GBSA calculations for each complex.

As can be seen in Table 2, the major term that favors the binding for both inhibitors are the vdW lipophilic term $\left(\Delta \mathrm{E}_{\mathrm{vdw}}\right)$. Interestingly, although the vast majority of the binding site residues are lipophilic residues, the electrostatic $\left(\Delta \mathrm{E}_{\text {ele }}\right)$ term still exhibits a significant contribution to the binding. The largest contributions to the $\Delta \mathrm{E}_{\text {ele }}$ term are from those residues that form H-bonds with the corresponding inhibitors, such as Asp97, Ser155 and Trp84 in Figure 4.This large contribution emphasizes the importance of the H-bond interactions which are electrostatic in nature. It would be also interesting to use certain advanced techniques, such as alanine-scanning (Lefèvre, Rémy, \& Masson, 1997; Morrison \& Weiss, 2001), to study the effect of mutations in residues responsible for these $\mathrm{H}$-bonding interactions. Research in this direction is currently in progress.

For $\mathbf{T L 3}$, the $\Delta \mathrm{E}_{\mathrm{vdW}}$ interaction is given by $-46.56 \mathrm{kcal} \cdot \mathrm{mol}^{-1}$, this value is slightly higher than that for $\mathbf{L} \mathbf{3}$ which is given by $-45.31 \mathrm{kcal} \cdot \mathrm{mol}^{-1}$. On the other hand, $\mathbf{L 3}$ exhibits a larger contribution from the $\Delta \mathrm{E}_{\text {ele }}$ term $(-33.54$ $\left.\mathrm{kcal} \cdot \mathrm{mol}^{-1}\right)$ than TL3 (-28.37) i.e., $\Delta \Delta \mathrm{E}_{\text {ele }}$ is equal to $5.17 \mathrm{kcal} \cdot \mathrm{mol}^{-1}$ which is almost equal to the energy contribution of a full H-bond. This larger contribution of the $\Delta \mathrm{E}_{\text {ele }}$ term for $\mathbf{L 3}$ than TL3 may be responsible for the fact that $\mathbf{L 3}$ is more active than TL3 in the in vitro assay (Swem et al., 2009; Chen et al., 2011). Regarding total binding energies as expressed by the $\Delta \mathrm{G}$ values, $\mathbf{L 3}$ shows higher binding energy according to the AMBER-MM/PBSA score $\left(-63.54 \mathrm{kcal} \cdot \mathrm{mol}^{-1}\right)$ than TL3 $\left(-59.11 \mathrm{kcal} \cdot \mathrm{mol}^{-1}\right)$. The same is true for the AMBER-MM/GBSA score of $\mathbf{L 3}\left(-48.65 \mathrm{kcal} \cdot \mathrm{mol}^{-1}\right)$ compared to that for TL3 $\left(-47.60 \mathrm{kcal} \cdot \mathrm{mol}^{-1}\right)$.

Decomposition of the binding energy on a per-residue basis is very important to understand the binding mode and assess the role of each residue in the binding. Figure 8 displays the per-residue binding energy analyses for the two complexes during the simulation period. For the $\Delta \mathrm{E}_{\mathrm{vdw}}$ and the $\Delta \mathrm{E}_{\text {ele }}$ interaction terms, only residues showing large contributions are selected. Figure 8a displays the per-residue contribution for the $\Delta \mathrm{E}_{\mathrm{vdW}}$ interaction term. As can be seen, the major contribution to the $\Delta \mathrm{E}_{\mathrm{vdw}}$ term is from the Tyr88 via a strong $\pi-\pi$ stacking interactions, consistent with the observations from the docking study. The contribution of this residue to the $\Delta \mathrm{E}_{\mathrm{vdw}}$ term for both inhibitors is similar, $-2.57 \mathrm{kcal} \cdot \mathrm{mol}^{-1}$ for $\mathbf{L 3}$ and $-2.59 \mathrm{kcal} \cdot \mathrm{mol}^{-1}$ for TL3. This is because the terminal aromatic ring which is responsible for the $\pi-\pi$ stacking interaction with this residue is identical in both inhibitors (L3 and TL3). The second most important $\Delta \mathrm{E}_{\mathrm{vdW}}$ interaction is from the Trp111 residue which contributes more to $\mathbf{T L 3}\left(-2.13 \mathrm{kcal} \cdot \mathrm{mol}^{-1}\right)$ than to $\mathbf{L 3}\left(-1.96 \mathrm{kcal} \cdot \mathrm{mol}^{-1}\right)$ as a result of the presence of the more lipophilic sulphur in TL3 instead of oxygen in $\mathbf{L 3}$.

Figure $8 \mathrm{~b}$ displays the per-residue contribution for the $\Delta \mathrm{E}_{\text {ele }}$ interaction term. The most important residue is Asp97 which contributes almost equally for the two inhibitors $\left(-11.83 \mathrm{kcal} \cdot \mathrm{mol}^{-1}\right.$ for $\mathbf{L 3}$ and $-11.35 \mathrm{kcal} \cdot \mathrm{mol}^{-1}$ for TL3). Differentiation for the $\Delta \mathrm{E}_{\text {ele }}$ term between the two inhibitors is from the Tyr80 and Trp84 residues which show the highest discrepancy between the two inhibitors. For $\mathbf{L} 3$, the $\Delta \mathrm{E}_{\text {ele }}$ contributions from the Tyr80 and the Trp84 residues are $-3.37 \mathrm{kcal} \cdot \mathrm{mol}^{-1}$ and $-2.88 \mathrm{kcal} \cdot \mathrm{mol}^{-1}$, respectively. For TL3, the contributions of these two residues are $-1.87 \mathrm{kcal} \cdot \mathrm{mol}^{-1}$ and $-2.03 \mathrm{kcal} \cdot \mathrm{mol}^{-1}$, respectively. The $\Delta \Delta \mathrm{E}_{\text {ele }}$ contribution between the two inhibitors from these two residues together is $2.35 \mathrm{kcal} \cdot \mathrm{mol}^{-1}$ which is almost half of the energy contribution of a full H-bond. This emphasizes the importance of these two residues for any future development of CviR antagonists. 
Table 2. Total and decomposed binding energies of the MD studied complexes $\left(\mathrm{kcal} \cdot \mathrm{mol}^{-1}\right)$ together with the experimental $\mathrm{IC}_{50}$ values

\begin{tabular}{|c|c|c|}
\hline \multirow[t]{2}{*}{ Contribution } & \multicolumn{2}{|c|}{ Inhibitor } \\
\hline & $\mathbf{L 3}$ & TL3 \\
\hline$\Delta \mathrm{E}_{\text {ele }}$ & -33.54 & -28.37 \\
\hline$\Delta \mathrm{E}_{\mathrm{vdW}}$ & -45.31 & -46.56 \\
\hline$\Delta \mathrm{E}_{\text {binding-gas }}{ }^{\mathrm{a}}$ & -78.85 & -74.93 \\
\hline$\Delta \mathrm{G}_{\text {binding }}(\text { AMBER-PBSA) })^{\mathrm{b}}$ & -63.54 & -59.11 \\
\hline$\Delta \mathrm{G}_{\text {binding }}(\text { AMBER-GBSA) })^{\mathrm{b}}$ & -48.65 & -47.60 \\
\hline
\end{tabular}
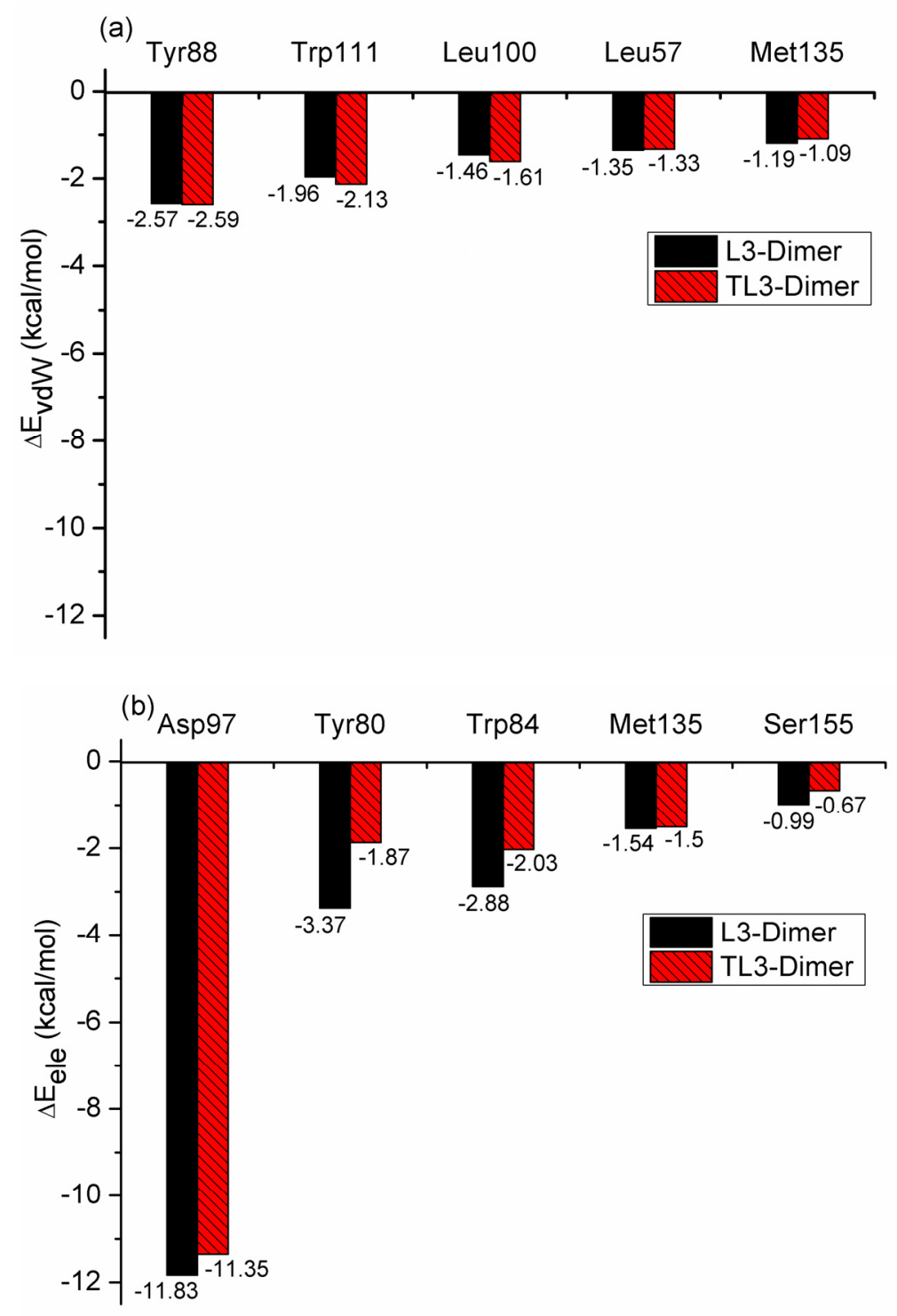

Figure 8. Per-residue binding energy decompositions calculated using the MMPBSA module of AMBER, (a) per-residue contribution to the vdW interaction term and (b) per-residue contribution to the electrostatic interaction term 


\section{Conclusions}

The exact binding modes of a series of recently synthesized and in vitro tested potential QS inhibitors were investigated in silico. Consistent with the experimentally measured $\mathrm{IC}_{50}$ values, this molecular modeling study using docking scores and energies of binding showed that the lactone based inhibitors indeed exhibit stronger binding properties than the thiolactone based class of inhibitors. Molecular dynamics simulations of different inhibitor-protein complexes further indicated that the lactone based inhibitors were more stable than the thiolactone based ones. Relative to the number of hydrophilic residues present in the binding site, the electrostatic effect made a significant contribution to the binding for the two series of inhibitors. Certain residues, such as Tyr80 and Trp84, were discriminating between the two series of inhibitors with a larger electrostatic contribution for the lactone than the thiolactone inhibitors.

\section{Acknowledgements}

MA acknowledges the Swinburne University Postgraduate Research Award (SUPRA). FW thanks the Victorian Partnership for Advanced Computing (VPAC) and Swinburne University supercomputing (Green/gSTAR) for the support on the computing facilities. The National Computational Infrastructure (NCI) at the Australian National University and the Victorian Life Sciences Computation Initiative (VLSCI) on its Peak Computing Facility at the University of Melbourne (an initiative of the Victorian Government, Australia) under the National Computational Merit Allocation Scheme (NCMAS) are acknowledged.

\section{References}

Ahmed, M., Sadek, M. M., Serrya, R. A., Kafafy, A.-H. N., Abouzid, K. A., \& Wang, F. (2013). Assessment of new anti-HER2 ligands using combined docking, QM/MM scoring and MD simulation. Journal of Molecular Graphics and Modelling, 40(0), 91-98. http://dx.doi.org/10.1016/j.jmgm.2012.12.001

Aiello, A. E., \& Larson, E. (2003). Antibacterial cleaning and hygiene products as an emerging risk factor for antibiotic resistance in the community. The Lancet Infectious Diseases, 3(8), 501-506. http://dx.doi.org/10.1016/S1473-3099(03)00723-0

Bayly, C. I., Cieplak, P., Cornell, W., \& Kollman, P. A. (1993). A well-behaved electrostatic potential based method using charge restraints for deriving atomic charges: the RESP model. Journal of Physical Chemistry, 97(40), 10269-10280. http://dx.doi.org/10.1021/j100142a004

Bottomley, M. J., Muraglia, E., Bazzo, R., \& Carfì, A. (2007). Molecular insights into quorum sensing in the human pathogen Pseudomonas aeruginosa from the structure of the virulence regulator LasR bound to its

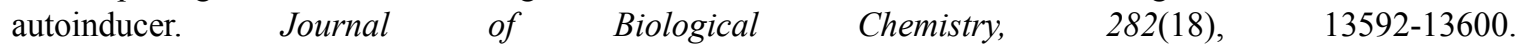
http://dx.doi.org/10.1074/jbc.M700556200

Chen, G., Swem, L. R., Swem, D. L., Stauff, D. L., O’Loughlin, C. T., Jeffrey, P. D., . . Frederick, M. (2011). A Strategy for Antagonizing Quorum Sensing. Molecular Cell, 42(2), 199-209. http://dx.doi.org/10.1016/j.molcel.2011.04.003

Deep, A., Chaudhary, U., \& Gupta, V. (2011). Quorum sensing and bacterial pathogenicity: From molecules to disease. Journal of Laboratory Physicians, 3(1), 4-11. http://dx.doi.org/10.4103/0974-2727.78553

Duan, Y., Wu, C., Chowdhury, S., Lee, M. C., Xiong, G., Zhang, W., . . Kollman, P. (2003). A point-charge force field for molecular mechanics simulations of proteins based on condensed-phase quantum mechanical calculations. Journal of Computational Chemistry, 24(16), 1999-2012. http://dx.doi.org/10.1002/jcc.10349

Estephane, J., Dauvergne, J., Soulère, L., Reverchon, S., Queneau, Y., \& Doutheau, A. (2008). N -Acyl-3-amino-5 H -furanone derivatives as new inhibitors of LuxR-dependent quorum sensing: Synthesis, biological evaluation and binding mode study. Bioorganic \& Medicinal Chemistry Letters, 18(15), 4321-4324. http://dx.doi.org/10.1016/j.bmcl.2008.06.090

Friesner, R. A., Murphy, R. B., Repasky, M. P., Frye, L. L., Greenwood, J. R., Halgren, T. A., . . Mainz, D. T. (2006). Extra Precision Glide:Docking and Scoring Incorporating a Model of Hydrophobic Enclosure for Protein-Ligand Complexes. Journal of Medicinal Chemistry, 49(21), 6177-6196. $\mathrm{http}: / / \mathrm{dx}$. doi.org/10.1021/jm051256o

Fuqua, W. C., Winans, S. C., \& Greenberg, E. P. (1994). Quorum sensing in bacteria: the LuxR-LuxI family of cell density-responsive transcriptional regulators. Journal of Bacteriology, 176(2), 269.

Galloway, W. R. J. D., Hodgkinson, J. T., Bowden, S. D., Welch, M., \& Spring, D. R. (2011). Quorum sensing in Gram-negative bacteria: Small-molecule modulation of AHL and AI-2 quorum sensing pathways. Chemical 
Reviews, 111(1), 28. http://dx.doi.org/10.1021/cr100109t

Galloway, W. R. J. D., Hodgkinson, J. T., Bowden, S., Welch, M., \& Spring, D. R. (2012). Applications of small molecule activators and inhibitors of quorum sensing in Gram-negative bacteria. Trends in Microbiology, 20(9), 449-458. http://dx.doi.org/10.1016/j.tim.2012.06.003

Geske, G. D., O’Neill, J. C., \& Blackwell, H. E. (2008). Expanding dialogues: from natural autoinducers to non-natural analogues that modulate quorum sensing in Gram-negative bacteria. Chemical Society Reviews, 37(7), 1432-1447. http://dx.doi.org/10.1039/b703021p

Geske, G. D., O’Neill, J. C., Miller, D. M., Mattmann, M. E., \& Helen, E. (2007). Modulation of bacterial quorum sensing with synthetic ligands: systematic evaluation of $\mathrm{N}$-acylated homoserine lactones in multiple species and new insights into their mechanisms of action. Journal of the American Chemical Society, 129(44), 13613-13625. http://dx.doi.org/10.1021/ja074135h

Geske, G. D., Wezeman, R. J., Siegel, A. P., \& Helen, E. (2005). Small molecule inhibitors of bacterial quorum sensing and biofilm formation. Journal of the American Chemical Society, 127(37), 12762-12763. http://dx.doi.org/10.1021/ja0530321

Ho, B. K., \& Agard, D. A. (2009). Probing the flexibility of large conformational changes in protein structures through local perturbations. PLoS Computational Biology, 5(4), 1000343. http://dx.doi.org/10.1371/journal.pcbi.1000343

Holmberg, S. D., Solomon, S. L., \& Blake, P. A. (1987). Health and economic-impacts of antimicrobial resistance Reviews of Infectious Diseases, 9(6), 1065-1078.

Jorgensen, W. L., Chandrasekhar, J., Madura, J. D., Impey, R. W., \& Klein, M. L. (1983). Comparison of simple potential functions for simulating liquid water. Journal of Chemical Physics, 79(2), 926-935. http://dx.doi.org/10.1063/1.445869

Kalia, V. C., \& Purohit, H. J. (2011). Quenching the quorum sensing system: potential antibacterial drug targets. Critical Reviews in Microbiology, 37(2), 121-140. http://dx.doi.org/10.3109/1040841X.2010.532479

Lefèvre, F., Rémy, M.-H., \& Masson, J.-M. (1997). Alanine-stretch scanning mutagenesis: a simple and efficient method to probe protein structure and function. Nucleic Acids Research, 25(2), 447-448. http://dx.doi.org/10.1093/nar/25.2.447

Levy, S. B. (2001). Antibiotic Resistance: Consequences of Inaction. Clinical Infectious Diseases, 33(Supplement 3), 124-129. http://dx.doi.org/10.1086/321837

Levy, S. B. (2002). Factors impacting on the problem of antibiotic resistance. Journal of Antimicrobial Chemotherapy, 49(1), 25-30. http://dx.doi.org/10.1093/jac/49.1.25

Levy, S. B., \& Marshall, B. (2004). Antibacterial resistance worldwide: causes, challenges and responses. Nature Medicine, 10, 122-129. http://dx.doi.org/10.1038/nm1145

McInnis, C. E., \& Blackwell, H. E. (2011). Thiolactone modulators of quorum sensing revealed through library design and screening. Bioorganic \& Medicinal Chemistry, 19(16), 4820-4828. http://dx.doi.org/10.1016/j.bmc.2011.06.071

Miller, M. B., \& Bassler, B. L. (2001). Quorum sensing in bacteria. Annual Review of Microbiology, 55(1), 165. http://dx.doi.org/10.1146/annurev.micro.55.1.165

Morrison, K. L., \& Weiss, G. A. (2001). Combinatorial alanine-scanning. Current Opinion in Chemical Biology, 5(3), 302-307. http://dx.doi.org/10.1016/S1367-5931(00)00206-4

Nasser, W., \& Reverchon, S. (2007). New insights into the regulatory mechanisms of the LuxR family of quorum sensing regulators. Analytical and Bioanalytical Chemistry, 387(2), 381-390. http://dx.doi.org/10.1007/s00216-006-0702-0

Okeke, I. N., Laxminarayan, R., Bhutta, Z. A., Duse, A. G., Jenkins, P., O'Brien, T. F., . . Klugman, K. P. (2005). Antimicrobial resistance in developing countries. Part I: recent trends and current status. The Lancet infectious diseases, 5(8), 481-493. http://dx.doi.org/10.1016/S1473-3099(05)70189-4

Rasmussen, T. B., Bjarnsholt, T., Skindersoe, M. E., Hentzer, M., Kristoffersen, P., Köte, M., . . Givskov, M. (2005). Screening for Quorum-Sensing Inhibitors (QSI) by Use of a Novel Genetic System, the QSI Selector. Journal of Bacteriology, 187(5), 1799-1814. http://dx.doi.org/10.1128/jb.187.5.1799-1814.2005

Reading, N. C., \& Sperandio, V. (2006). Quorum sensing: the many languages of bacteria. FEMS Microbiology 
Letters, 254(1), 1-11. http://dx.doi.org/10.1111/j.1574-6968.2005.00001.x

Rocha, G. B., Freire, R. O., Simas, A. M., \& Stewart, J. J. P. (2006). RM1: A reparameterization of AM1 for H, C, $\mathrm{N}, \mathrm{O}, \mathrm{P}, \mathrm{S}, \mathrm{F}, \mathrm{Cl}, \mathrm{Br}$, and I. Journal of Computational Chemistry, 27(10), 1101-1111. http://dx.doi.org/10.1002/jcc.20425

Sabbah, M., Fontaine, F., Grand, L., Boukraa, M., Efrit, M. L., Doutheau, A., Soulère, L., \& Queneau, Y. (2012). Synthesis and biological evaluation of new N-acyl-homoserine-lactone analogues, based on triazole and tetrazole scaffolds, acting as LuxR-dependent quorum sensing modulators. Bioorganic \& Medicinal Chemistry, 20(15), 4727-4736. http://dx.doi.org/10.1016/j.bmc.2012.06.007

Sadek, M. M., Serrya, R. A., Kafafy, A.-H. N., Ahmed, M., Wang, F., \& Abouzid, K. A. M. (2013). Discovery of new HER2/EGFR dual kinase inhibitors based on the anilinoquinazoline scaffold as potential anti-cancer agents. Journal of Enzyme Inhibition and Medicinal Chemistry, 1, 1-8. http://dx.doi.org/0.3109/14756366.2013.765417

Schwobel, J., Ebert, R., Kuhne, R., \& Schuurmann, G. (2009). Prediction of the Intrinsic Hydrogen Bond Acceptor Strength of Chemical Substances from Molecular Structure. The Journal of Physical Chemistry A, 113(37), 10104-10112. http://dx.doi.org/10.1021/jp904812b

Sjöblom, S., Brader, G., Koch, G., \& Palva, E. T. (2006). Cooperation of two distinct ExpR regulators controls quorum sensing specificity and virulence in the plant pathogen Erwinia carotovora. Molecular Microbiology, 60(6), 1474-1489. http://dx.doi.org/10.1111/j.1365-2958.2006.05210.x

Skovstrup, S., Quement, L., Thordal, S., Hansen, T., Jakobsen, T. H., Harmsen, M., . . Taboureau, O. (2013). Identification of LasR Ligands through a Virtual Screening Approach. ChemMedChem, 8(1), 157-163. http://dx.doi.org/10.1002/cmdc.201200434

Soulère, L., Frezza, M., Queneau, Y., \& Doutheau, A. (2007). Exploring the active site of acyl homoserine lactones-dependent transcriptional regulators with bacterial quorum sensing modulators using molecular mechanics and docking studies. Journal of Molecular Graphics and Modelling, 26(2), 581-590. http://dx.doi.org/10.1016/j.jmgm.2007.04.004

Soulère, L., Guiliani, N., Queneau, Y., Jerez, C. A., \& Doutheau, A. (2008). Molecular insights into quorum sensing in Acidithiobacillus ferrooxidans bacteria via molecular modelling of the transcriptional regulator AfeR and of the binding mode of long-chain acyl homoserine lactones. Journal of Molecular Modeling, 14(7), 599-606. http://dx.doi.org/10.1007/s00894-008-0315-y

Soulère, L., Sabbah, M., Fontaine, F., Queneau, Y., \& Doutheau, A. (2010). LuxR-dependent quorum sensing: Computer aided discovery of new inhibitors structurally unrelated to $\mathrm{N}$-acylhomoserine lactones.

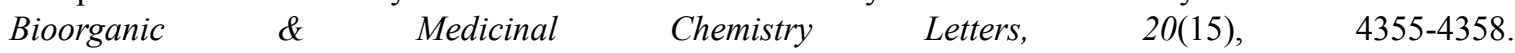
http://dx.doi.org/10.1016/j.bmcl.2010.06.081

Stauff, D. L., \& Bassler, B. L. (2011). Quorum Sensing in Chromobacterium violaceum: DNA Recognition and Gene Regulation by the CviR Receptor. Journal of Bacteriology, 193(15), 3871-3878. http://dx.doi.org/10.1128/jb.05125-11

Suga, H., \& Smith, K. M. (2003). Molecular mechanisms of bacterial quorum sensing as a new drug target. Current Opinion in Chemical Biology, 7(5), 586-591. http://dx.doi.org/10.1016/j.cbpa.2003.08.001

Swem, L. R., Swem, D. L., O’Loughlin, C. T., Gatmaitan, R., Zhao, B., Ulrich, S. M., \& Bassler, B. L. (2009). A quorum-sensing antagonist targets both membrane-bound and cytoplasmic receptors and controls bacterial pathogenicity. Molecular Cell, 35(2), 143-153.

Swem, L. R., Swem, D. L., Wingreen, N. S., \& Bassler, B. L. (2008). Deducing Receptor Signaling Parameters from In Vivo Analysis: LuxN/AI-1 Quorum Sensing in Vibrio harveyi. Cell, 134(3), 461-473. http://dx.doi.org/10.1016/j.cell.2008.06.023

Voter, A. F. (1997). A method for accelerating the molecular dynamics simulation of infrequent events. The Journal of Chemical Physics, 106(11), 4665-4677. http://dx.doi.org/10.1063/1.473503

Wang, J., Wolf, R. M., Caldwell, J. W., Kollman, P. A., \& Case, D. A. (2004). Development and testing of a general amber force field. Journal of Computational Chemistry, 25(9), 1157-1174. http://dx.doi.org/10.1002/jcc.20035

Waters, C. M., \& Bassler, B. L. (2005). Quorum sensing: cell-to-cell communication in bacteria. Annual Review of Cell and Developmental Biology, 21, 319-346. 
http://dx.doi.org/10.1146/annurev.cellbio.21.012704.131001

Zhang, R., Pappas, T., Brace, J. L., Miller, P. C., Oulmassov, T., Molyneaux, J. M., . . . Joachimiak, A. (2002). Structure of a bacterial quorum-sensing transcription factor complexed with pheromone and DNA. Nature, 417(6892), 971-974. http://dx.doi.org/10.1038/nature00833

\section{Copyrights}

Copyright for this article is retained by the author(s), with first publication rights granted to the journal.

This is an open-access article distributed under the terms and conditions of the Creative Commons Attribution license (http://creativecommons.org/licenses/by/3.0/). 